

\section{EXPEDIENTE}

Universidade do Estado do Rio de Janeiro - UERJ

Instituto de Estudos Sociais e Políticos - IESP

CADERNOS DE ESTUdOS SOCIAIS E POLÍTICOS www.e-publicacoes.uerj.br/index.php/CESP

\section{COMITÉ EDITORIAL}

Anna Carolina Venturini, IESP-UERJ

Felipe Munhoz de Albuquerque, IESP-UERJ

Leonardo Nóbrega da Silva, IESP-UERJ

Marcelo Borel, IESP-UERJ

Marcia Rangel Candido, IESP-UERJ

Marina Rute Pacheco, IESP-UERJ

Mariane Silva Reghim, IESP-UERJ

Natália Leão, IESP-UERJ

Paulo Joaquim Da Silva Rodrigues, IESP-UERJ

Raul Nunes de Oliveira, IESP-UERJ

\section{CAPA, LAYOUT E DIAGRAMAÇÃO}

Marcia Rangel Candido

Raul Nunes de Oliveira 


\section{Apresentação}

Mariane Silva Reghim

\section{Dossiê}

É Possível Fazer Ciências Sociais sem uma Análise Crítica das

Categorias de Diferenciação? Uma Proposição Feminista

Natália Corazza Padovani

As Perspectivas Teóricas Queer e o Uso Cotidiano da Língua

Portuguesa

Helza Ricarte Lanz e Juliane Noack Napoles

Raça e Violência Sexual: Âmbito de Aplicação da Vitimodogmática?

Amanda Bessoni Boudoux Salgado e José Roberto Macri Jr.

What Happened with "What Happened, Miss Simone?"? - Assistindo ao Documentário Pela Ótica do Feminismo Negro

Rafael Pinto Ferreira de Queiroz

O Racismo Institucional no Brasil: Contribuições de Louis Althusser para o Debate

\section{Artigos}

O Voto Econômico na América Latina entre 2004 - 2012: Avaliação da Economia e do Desempenho do Governo em Políticas Públicas e de Combate à Corrupção

Flávia Bozza Martins

Eleições Presidenciais de 2014: Reflexões sobre o Capital Político e a

Capitalização de Votos de Marina Silva

Bruno Fonseca Gurão e Mirna Tonus

\section{Resenha}

Neoliberalismo Desde Baixo, Pós-Fordismo Periférico e Cálculos Emancipatórios

Igor Peres

Sobre Autogestão nas Fábricas Recuperadas no Brasil: (R)Existindo no Mercado 


\title{
As Perspectivas Teóricas Queer e o Uso Cotidiano da Língua Portuguesa
}

\author{
Queer Theoretical Perspectives and Everyday Usage of the Portuguese Language
}

\author{
Helza Ricarte Lanz ${ }^{1}$ \\ Juliane Noack Napoles ${ }^{2}$
}

\section{RESUMO}

O objetivo desse artigo é refletir sobre as contribuições da perspectiva teórica queer e o uso cotidiano da língua portuguesa. $\mathrm{O}$ artigo está divido em três partes: primeiramente, apresentaremos a perspectiva teórica queer e alguns de seus conceitos básicos que nos servirão de base para inferirmos o valor da língua dentro dessa abordagem. Na segunda parte, apontaremos três exemplos do uso cotidiano da língua portuguesa e, dentro da perspectiva queer, discutiremos possíveis significados dessa prática social. Na terceira parte, focaremos algumas possíveis consequências da perspectiva teórica queer. Concluímos o artigo apontando para as contribuições queer, os novos impulsos revisionistas e questionamos o risco de uma aporia teórica.

PALAVRAS CHAVE: Teoria queer; Língua portuguesa; Sexo; Gênero; Subjetividades.

\begin{abstract}
This article reflects on the theoretical contributions of the queer perspective and the usage of the Portuguese language. This paper is divided in three parts. Initially, the queer perspective and some of its basic concepts will be presented, concerning the Portuguese language and its usage. The second part, based on three examples of language usage, will discuss some meanings of its social practice. The third part focuses on the consequences of the queer perspective. As a conclusion, this paper indicates the queer theory's contributions, its revisionist impulses and the risk of a theoretical dead-end
\end{abstract}

KEYWORDS: Queer theory; Portuguese language; Sex; Gender; Subjectivities.

1 Pós-doutoranda em Educação na Universität zu Köln. E-mail: hl@,drlanz.org

2 Pós-Doutora em Ciências da Educação pela PUC-MG. E-mail: jnoackna@,uni-koeln.de 


\section{INTRODUÇÃO}

O objetivo desse artigo é refletir sobre as contribuições teóricas queer no uso cotidiano da língua portuguesa e desvendar, dentro de uma perspectiva teórica queer, algumas normas e visões de mundo. As línguas, dentro de uma perspectiva antropológica, influenciam decisivamente a nossa maneira de pensar, o nosso modo de ver a realidade e, consequentemente, a nossa visão de mundo e as nossas ações. Línguas são produtos simbólico-culturais que espelham normas e valores de uma sociedade e influenciam nossas ações cotidianas. A hipótese de Sapir-Whorf, segundo a qual é através da língua que construímos a nossa visão de mundo, ainda que questionável em alguns aspectos, nos permite entender a relação entre língua, linguagem e sociedade (WHORF, 1994).

Nesse contexto, o presente artigo será dividido em três partes: na primeira parte, apresentaremos a perspectiva teórica queer e alguns de seus conceitos centrais que nos servirão de base para inferir o valor da língua nessa relação. Na segunda parte, apontaremos três exemplos de uso do masculino genérico e, dentro da perspectiva queer, discutiremos possíveis significados dessa prática cotidiana. O genérico masculino - pronomes, substantivos e adjetivos - é utilizado normalmente quando o gênero é desconhecido, ou quando é atribuído a um grupo de pessoas, incluindo homens e mulheres. Finalizando, na terceira parte focaremos algumas possíveis consequências da perspectiva teórica queer. Assim como Michael Warner (1991), estamos convencidas de que não se trata apenas de uma análise ou descoberta de práticas e discursos heteronormativos, mas, principalmente, de uma desestabilização, crítica e intervenção nesse sistema normalizador: "o alvo da teoria social queer, nesse contexto como em muitos outros, deve ser de confronto à heteronormatividade da cultura moderna [...]” (WARNER, 1991: 16).

\section{O QUADRO TEÓRICO QUEER E A LÍNGUA}

A palavra queer vem do inglês e significa estranho, esquisito, aquilo que incomoda; na gíria tem a conotação de "cortar o barato de alguém" e, numa conotação pejorativa, a palavra foi utilizada para difamar pessoas homossexuais (DEGELE, 2005; MISKOLCI, 2009). 
Concomitantemente, pelo menos a partir da década de 1980, esse grupo de pessoas adotou orgulhosamente esse termo que hoje vigora como um conceito político para o movimento LGBTQ (Lésbicas-Gays-Bissexuais-Transexuais-Queer). Consequentemente, esse conceito queer é utilizado por quem, na sua orientação sexual ou identidade de gênero, não se deixa (ou não se quer) posicionar dentro de uma ordem binária, isto é, ou homem, ou mulher. Ao mesmo tempo, no contexto acadêmico, surgem as raízes dos estudos queer, tanto na linguística (como também na ciência literária) e na psicanálise, quanto na filosofia. O termo "teoria queer" nasceu numa conferência, em 1989, em Santa Cruz na Califórnia (EUA), quando Teresa de Lauretis empregou essa denominação para contrastar com os estudos lésbicos e gays (DEGELE, 2005; MILKOLCI, 2009).

O conceito pode ser caracterizado como dinâmico, multifacetado, e foi criado como um impulso revisionista e crítico para questões relacionadas à identidade e às relações de poder nas áreas de sexualidade e gênero (HARTMANN, 2013: 267). Seu foco é desconstruir, a partir de meios científicos, a sexualidade enquanto norma binária e organizada compulsoriamente como ações heterossexuais (DEGELE, 2005). A crítica se dirige à normatização de gênero e sexualidade (NOACK NAPOLES, 2017). Como afirma Degele (2005), criticam-se: “[...] instituições (como o casamento), ideologias (como o estilo feminino de liderança) e a lógica do pensamento binário, cujos resultados se encontram presentes tanto na sociobiologia quanto na filosofia" (DEGELE, 2005: 15, tradução nossa). Atribuímos a tal normatização (socialmente normalizadora e estruturadora) a utilização conceitual que naturaliza irrefletidamente a binariedade e heterossexualidade. A teoria queer, como afirma Mörth (2005), “[...] é uma teoria que se contrapõe a todas as construções e normalizações indenitárias reguladoras” (MÖRTH, 2005: 39, tradução nossa). Assim sendo,

\footnotetext{
não se trata de uma possibilidade, de uma estratégia de tolerância ou reconhecimento de pessoas que não se enquadram em categorias binárias, mas abordar práticas, sistemas, instituições e discursos, cujo desvio ou perversão (sexual) está sendo produzida e reproduzida, criando normas bi- e heterossexuais que privilegiam certas existências e formas de vida (KLAPEER, 2015: 30, tradução nossa).
}

Teóricas e teóricos queer, tais como Eve K. Sedgwick, David M. Halperin, Judith Butler e Michael Warner, começaram a empreender análises sociais que incidem sobre os vários níveis da ordem social e retomaram a proposta de Foucault, ao estudar a sexualidade como um dispositivo 
histórico do poder que marca as sociedades ocidentais modernas e se caracteriza pela inserção do sexo em sistemas de unidade e regulação social (FOUCAULT, 2005). Os estudos queer não pretendem ser vistos simplesmente como uma expansão teórica das pesquisas de gênero, mas sim como estudos cujo objetivo se encontra na reconstrução da “[...] gênese do poder estruturador da normatividade e dos processos normativos de instituições e regras, e seus significados intrínsecos de sexualidade" (DEGELE, 2005: 17, tradução nossa).

Nesse contexto de gênero, estabeleceu-se um conceito central de heteronormatividade (DEGELE, 2005; HARTMANN, 2012; KLAPEER, 2015; WAGENKNECHT, 2004), através do qual o interesse de conhecimento é direcionado à heterossexualidade enquanto princípio organizacional político e social. Klapeer (2015) afirma que o conceito de heteronormatividade, apesar da sua complexidade e multidimensionalidade, é definido frequentemente de forma inadequada ou analisado insuficientemente. Não obstante, impõe-se uma definição estática “[...] como um conceito que descreve as normas (sociais) de uma bi- e heterossexualidade, e a partir da mesma, todas as formas de vida e pessoas que não se enquadram (que não querem ou não podem se enquadrar) são afetadas [...]” (KLAPEER 2015: 25, tradução nossa). Wagenknecht (2004) afirma, além disso, que a heteronormatividade impõe às pessoas, na forma binária de corporalidade e gêneros socialmente distintos, uma atração sexual direcionada ao sexo "oposto". Assim sendo, a heteronormatividade age como uma categoria a priori de compreensão, define e gera um conjunto de normas comportamentais, regula a produção de conhecimento, estrutura os discursos, orienta as ações políticas, determina a distribuição de recursos e atua como modo de atribuição na divisão de trabalho (WAGENKNECHT, 2004).

A heteronormatividade descreve "[...] um sistema sexual binário, dentro do qual apenas dois gêneros são aceitos, equiparando sexo, orientação sexual, papéis sexuais com a identidade de gênero: as bases são homens e mulheres, que na sua sexualidade se relacionam por oposição" (DEGELE 2005: 19, tradução nossa). A partir dessa premissa de heteronormatividade, afirma-se que os seres humanos estão "naturalmente" organizados sexualmente de forma binária e que se relacionam mutuamente de forma oposta. Baseado nisso, Nina Degele (2005) sugere a seguinte definição:

Heteronormatividade é um sistema binário de gêneros organizados heterossexualmente que determinam modos de percepção, de ação e de pensar, que como uma instituição social básica naturalizada por heterossexualidade e dois gêneros contribui e deve 
contribuir para um automatismo inteligível de visão do mundo e para a redução de complexidade (DEGELE, 2005: 19, tradução nossa).

$\mathrm{Na}$ sua definição, Degele (2005) diferencia analiticamente dois aspectos. (1) O aspecto estruturante, no que diz respeito à invisibilidade não questionada e tida como óbvia da heterossexualidade e binarismo de gêneros, e seu significado para as instituições sociais e dentro das mesmas. A eficácia dos mecanismos atuantes é descrita por ela como "naturalização", "inconsciência" e "institucionalização". (2) O aspecto funcional focaliza os efeitos da heteronormatividade, pelo qual principalmente os mecanismos reducionistas de orientação no mundo são simplificados. Degele (2005) fala, nesse sentido, de uma "redução de complexidade". Segundo a autora, isso resulta em quatro características de heteronormatividade:

1. Naturalização - Heteronormatividade resulta de processos sociais normalizadores que "naturalizam" heterossexualidade e gêneros binários, isto é, dá a uma prática e a um discurso socialmente construídos uma falsa aparência de naturalidade.

2. Inconsciência - Os valores e as normas podem não ser conscientes para as pessoas envolvidas, porém atuam como um hábito (BOURDIEU apud DEGELE, 2005). De acordo com isso, a heteronormatividade "[...] interioriza os parâmetros discursivos da sociedade, o que gera estrategicamente uma orientação prática e uma certa corporalidade, sem que a estratégia produzida seja necessariamente consciente" (BOURDIEU apud DEGELE, 2005: 20).

3. Institucionalização de estruturas - A heteronormatividade serve como âncora tanto para o indivíduo (na mente e no corpo), quanto para as estruturas sociais.

4. Redução de complexidade - A heteronormatividade penetra não apenas nas regras institucionais, como também na comunicação e nas relações sociais (BOURDIEU apud DEGELE, 2005). Essas características podem servir igualmente como instrumento e categorias de análise queer e, assim, permitir desconstruir o automatismo das mesmas. O objetivo da crítica desse sistema de ordem natural “[...] é tornar visível os mecanismos (de poder) para desnaturalizá-lo, bem como mostrar as quebras e anomalias [...]” (MÖRTH, 2005: 41, tradução nossa).

O interesse de conhecimento se direciona a saber, dentro do contexto linguístico atual, como as categorias de gênero foram e são construídas enquanto suposto sistema natural de ordem. Judith Butler (1991) levantou essa questão em seus estudos queer e, mais especificamente, no seu trabalho pioneiro "Gender Trouble". Nesse trabalho, a autora questiona: 


\begin{abstract}
como a língua produz ela mesma a construção fictícia de gênero que alimenta os distintos regimes de poder? Quais continuidades entre sexualidade (sexo), identidade sexual (gênero) e prazer (cobiça, atração) são sugeridas pela língua que imputa heterossexualidade? (BUTLER, 1991: 10).
\end{abstract}

A relação entre língua e gênero pode ser retratada a partir de várias perspectivas, porém a ligação entre o uso da língua e a socialização de gênero tem se popularizado muito recentemente, o que, relacionado a esse conhecimento, implica a exigência de um uso mais sensível da língua no que tange à sexualidade e ao gênero (VENEGAS FRANCO e PÉREZ CERVERA, 2006).

Existem práticas linguísticas diversas que podem levar a uma hierarquia de gêneros:

\begin{abstract}
como a transmissão dos sobrenomes (nomes de família), na qual tradicionalmente se mantém o sobrenome do homem, seja este o pai ou o marido [prática que até certo ponto tem aos poucos mudado, observação nossa]; ou a famosa "regra" de derivação do feminino a partir do masculino, muito frequente em gramáticas normativas e métodos de língua estrangeira, segundo a qual o feminino se forma pelo acréscimo da desinência - a (no caso do português) ao radical masculino (guardando uma intrigante analogia com o mito de criação judaico-cristão, segundo o qual a mulher foi criada a partir do homem) sem, no entanto, explicar por que a forma masculina seria mais básica que a forma feminina (MÄDER, 2015: 27).
\end{abstract}

Nesse artigo, enveredaremos pela perspectiva da gramática portuguesa, onde focaremos “[...] no sentido restrito, mas seguramente no sentido mais usual sobre as regularidades morfológicas e sintáticas de uma língua" (JÜRGENS 1999: 13). A escolha da língua portuguesa se dá pela sua expressão a nível planetário, dado ser uma língua falada nos cinco continentes: a) como língua materna em Portugal e no Brasil; b) como língua segunda, língua oficial, em Angola, Cabo Verde, Guiné-Bissau, Moçambique, São Tomé e Príncipe; c) como língua co-oficial em Timor Leste, além do tétum, e em Macau, além do chinês. É a língua de herança (na terminologia anglo-saxônica) por falantes que migraram para outros espaços e territórios nacionais. Essa extensão de vozes, de sujeitos e de lugares em geral, e as práticas da língua portuguesa no Brasil em particular, contribuem para a difusão de saberes e práticas que estruturam toda a vida institucional e cultural de nosso tempo. Dessa forma, a língua portuguesa é uma língua de comunicação internacional e requer um olhar mais atento para os processos sociais normalizadores que criam classificações marcadas pela produção simultânea do hegemônico e do subalterno. Sob o ponto de vista dos estudos queer, a partir de alguns exemplos, analisaremos o masculino genérico no uso cotidiano da língua portuguesa. 


\section{EXEMPLOS DO MASCULINO GENÉRICO SOB A PERSPECTIVA TEÓRICA QUEER}

$\mathrm{Na}$ linguística, diferencia-se entre o masculino genérico e o masculino específico, sendo o primeiro utilizado nos casos em que o masculino engloba o feminino, tornando a presença do feminino invisível. O masculino específico se refere exclusivamente aos nomes, seres e coisas masculinos. Entre o gênero gramatical, o gênero social e o sexo biológico, em especial, não existe a priori uma relação constituinte (BORGES, 2013), fato que vem sendo questionado pela linguística não sexista, tanto no Brasil quanto na Alemanha (PUSCH, 1984).

Com relação à língua alemã, existem diversos questionamentos e pesquisas históricas que buscam verificar a origem do genérico masculino, a partir de quando ou se este sempre existiu na língua alemã (DOLESCHAL 2002). O masculino genérico é definido pelo dicionário alemão DUDEN (1984) da seguinte forma:

\footnotetext{
O genérico masculino é usado principalmente nas denominações profissionais e substantivos que designam protagonistas/titulares de uma ação (Nomina agentis), quando o sexo biológico/gênero não tiver importância [sic] ou quando homens e mulheres são igualmente abrangidos. O genérico masculino é visto/sentido nesse caso como neutro e, respectivamente, como generalizante (DUDEN, 1984: 200, tradução nossa, grifo nosso).
}

Segundo Mäder (2015), a própria palavra "gênero" é intrigante, já que a sua raiz latina, genus, cognata do grego yévos [génos], remete à ideia de nascimento, origem - gênese (ERNOUT; MEILLET; ANDRÉ, 2001 apud MÄDER, 2015). Seu significado, no entanto, estende-se aos seres que têm semelhanças naturais às coisas abstratas e inanimadas classificáveis numa mesma categoria, como os gêneros gramaticais, que organizam nomes em diferentes categorias. É ponto pacífico afirmarmos gramaticalmente que em português existem dois gêneros: o masculino e o feminino.

Portanto, em português, os nomes estão divididos em duas classes, e o gênero do nome determinará o gênero dos elementos relacionados sintaticamente a ele. No entanto, é possível que os elementos que concordam sintaticamente com os nomes (adjetivos, artigos, pronomes etc.) possam apresentar uma menor variedade de formas morfossintáticas, por exemplo, adjetivos como alegre, triste, ou numerais como três, quatro, os quais apresentam uma única forma para o masculino e o feminino (MÄDER, 2015: 41). 
A gramática portuguesa nos oferece, ou melhor, nos impõe a possibilidade de expressar a distinção entre masculino e feminino. E o fato de a língua portuguesa "forçar" o seu usuário a uma escolha entre gênero masculino e gênero feminino, força-o também ao perfilamento de um conceito num frame semântico.

\section{TRÊS EXEMPLOS DE USO DO MASCULINO GENÉRICO}

A necessidade de denotar o gênero humano na língua portuguesa leva muitas vezes a uma escolha entre dois gêneros gramaticais (masculino ou feminino) para desempenhar uma função, o que nos leva à pergunta: por que se escolhe um gênero (masculino, como universal) e não o outro (feminino, como universal)? Antes de buscar uma resposta a esta questão, veremos a seguir alguns dos muitos outros exemplos de uso do masculino genérico.

\section{$1^{\circ}$ Exemplo: O plural}

O plural de grupos de sujeitos e objetos femininos e masculinos é construído, em muitos casos em português, acrescentando-se às raízes das palavras as letras designando feminino (-a) ou masculino (-o) e a letra s. Nos casos em que, num grupo feminino, encontra-se um elemento masculino, é usual que o plural seja construído no masculino. Por exemplo, numa sala de aula formada por vinte e oito meninas e um único menino, é comum atribuir ao conjunto de alunas e alunos a denominação genérica "os alunos”. Numa perspectiva linguística, espelha-se aqui o que é discutido como "gênero não marcado" 3 , o que justifica linguisticamente o uso do genérico masculino, sem refletirmos os significados sociais e políticos inerentes a essa prática social. Mäder (2015) resume:

\footnotetext{
Assim, a justificativa atual para o uso do masculino genérico em português é a de que o gênero gramatical masculino é o gênero "não marcado", e que o mesmo seria adequado tanto à denotação de seres humanos do gênero masculino quanto à de seres humanos do gênero feminino. O gênero gramatical masculino, enquanto gênero "não marcado", segundo alguns autores, não carregaria uma "marca" semântica de gênero, ao contrário
}

3 O conceito de marca foi adaptado por Jakobson, ainda nos anos 1930, para relações semânticas, e já então aplicado a oposições lexicais como masculino/feminino (por exemplo осел/ослица [osël/oslíca] 'asno/asna') (HASPELMATH, 2006 apud MÄDER, 2015). 
do gênero gramatical feminino, que seria o gênero "marcado", carregando uma marca semântica de 'feminino' (MÄDER, 2015: 103).

Exemplos cotidianos banais nos mostram essa prática social:

Exemplo a) Os médicos estão sobrecarregados com os desafios da saúde pública;

Exemplo b) Os brasileiros avançaram muito na pesquisa contra o Zika;

Exemplo c) A reunião de professores foi adiada devido à tempestade.

Em nenhum dos exemplos acima podemos afirmar que estamos nos referindo também a mulheres. A primeira e a última frases, exemplificando, sugerem que o efeito de gênero "não marcado" possa estar relacionado a fatores extralinguísticos, entre outros, como os estereótipos de gênero associados às diferentes categorias profissionais. Poderíamos nos questionar se, nos exemplos a), b) e c) citados acima, o efeito de gênero não marcado se deve à proporção de homens e mulheres nas respectivas profissões. No entanto, nas práticas cotidianas sociais, mesmo quando temos um número expressivamente maior de pessoas do gênero feminino, o masculino é utilizado como gênero universal. Essa prática tem consequências reais. Assim, vejamos: pensamos conscientemente no exemplo a) que há (mulheres) médicas empenhadas nos desafios da saúde pública? Podemos saber definitivamente no exemplo b), se há ou se não há pesquisadoras (mulheres) pesquisando o vírus Zika? No exemplo c), será que percebemos conscientemente que há não apenas professores (homens) mas também professoras (mulheres) que participarão da reunião adiada? É obvio podermos afirmar que em nenhuma dessas frases se identifica claramente um grupo de pessoas no qual há mulheres e homens. O masculino é masculino específico e o genérico não é neutro, mas sexuado. É necessário nomear a mulher para que ela esteja representada num enunciado.

\section{$2^{\circ}$ Exemplo: Mãe - Pai $=$ Pais}

Outro caso intrigante está relacionado à designação de parentesco, onde permeiam não apenas papéis, mas expectativas sociais extra-linguísticas. Exemplificando, temos a palavra mãe para designar uma relação de parentesco cujo papel social é claramente identificado como aquela pessoa que gera e cria uma criança ou que a adota e, em um caso ou no outro, essa pessoa cumpre com sua tarefa socializadora de formar esse novo membro. Da mesma forma, temos a palavra pai para designar uma relação de parentesco cujo papel social é claramente identificado, na nossa 
sociedade, como aquela pessoa que é genitora de uma criança ou adotou-a e, num caso ou no outro, cumpre com sua tarefa socializadora de formar esse novo membro. Aparentemente, temos até então denominações linguísticas distintas para uma divisão relativamente equitativa de papéis sociais, mesmo que, na prática cotidiana, essa igualdade de papéis sociais e de atuação de ambas as partes na formação de crianças sejam ilusórias (RICARTE LANZ, 2006). Na formação linguística de plural, temos que o masculino plural pais designará o conjunto de pai e mãe, estabelecendo-se uma hierarquia entre os gêneros e colocando as mulheres, mães, em segundo plano em relação aos homens, pais - o que de fato representa uma relação assimétrica entre os gêneros - um sexismo gramatical.

A língua portuguesa usa o sistema de primazia do masculino também em pares de palavras de gêneros diversos que se referem aos mesmos papéis quando colocados juntos: pai e mãe = pais, filho e filha $=$ filhos. Nesse sentido, é também interessante mencionar que muitas obras clássicas da literatura mundial, tais como "Romeu e Julieta", de Shakespeare, ou a lenda medieval europeia Tristão e Isolda (reescrita por vários autores e mencionada aqui apenas a título de ilustração) são colocados na ordem: gênero masculino, seguido do gênero feminino, o que indica que a mulher vem sempre depois do homem - daí Simone de Beauvoir denominar o gênero feminino de "o segundo sexo". No plural dos gêneros de parentesco, a mulher é nominalmente excluída (CALDAS COULTHARD, 2007 apud MÄDER, 2015).

\section{$3^{\circ}$ Exemplo: Mulher e Homem $=$ Homens}

Outro caso mais complicado de masculino genérico é o uso de uma palavra que, modificada ao longo da história, designa, simultaneamente, o ser humano do gênero masculino (sentido específico) e os seres humanos como espécie animal: os homens (sentido genérico).

\footnotetext{
Em latim, havia três palavras para classificar esse mesmo domínio da experiência: homo, para a espécie; uir, para os homens (sentido específico); e femina, para as mulheres. Em algum período da evolução do latim para o português esse sistema se reorganizou. A palavra uir tornou-se obsoleta e seu conteúdo foi assimilado pela palavra homo, que evoluiu em homem no português. (MÄDER, 2015: 91, grifo nosso)
}

A utilização do genérico masculino, como anteriormente mencionado, está linguisticamente relacionada ao conceito de nome marcado e nome não marcado, do qual se deduz uma neutralidade 
com uma suposta insignificância social e política - o que de fato não o é. Como afirmam muitas autoras sensíveis a um uso não-sexista da língua,

as palavras não podem significar algo diferente do que nomeiam. O conjunto da humanidade está formado [não apenas!] por mulheres e homens, mas em nenhum caso a palavra homem representa a mulher (VENEGAS FRANCO; PÉREZ CERVERA, 2006: 17, grifo nosso).

Citamos os três exemplos acima que, cremos nós, servem para ilustrar o caráter androcêntrico da língua e da linguagem. Esses exemplos serão confrontados agora com as abordagens da teoria queer.

\section{AS CONTRIBUIÇÕES QUEER, LÍNGUA E LINGUAGEM}

A língua é um fato tão cotidiano que a assumimos como algo natural e poucas vezes nos detemos a perguntar sobre a sua importância. Através da língua aprendemos a nomear o mundo em função dos valores imperantes na sociedade. Assim sendo, as palavras determinam não apenas as coisas, mas também a visão de mundo, as normas e os valores sociais, os sentimentos, as diferenças. Atribuímos à língua uma importância constituinte e estruturadora da realidade. Isso se mostra, por exemplo, na ideia central do conceito linguístico de marca. O conceito de marca da linguística está presente na teoria queer. A questão que Butler (1991) coloca é: "O feminino resiste às representações da língua? [...] Ou é o 'feminino’ o único gênero que é representado numa língua que funde o gênero e o sexo?” (BUTLER, 1991: 10). Nesse sentido, algumas teóricas argumentam,

\footnotetext{
segundo Simone de Beauvoir, apenas a identidade de gênero feminina é, como tal, marcada, enquanto a identidade de gênero masculina funde-se com a concepção de uma pessoa universal, o que define a mulher através do gênero, os homens são celebrados, ao contrário, enquanto portadores de uma personalidade universalizada que se estende além da sua corporalidade (BUTLER, 1991: 27, tradução nossa).
}

Os três exemplos que discutimos nesse artigo mostram claramente o caráter universalizador hegemônico do uso do gênero masculino genérico. A teoria queer foca em um amplo campo de normalização como lócus de violência social: as estruturas sociais hegemônicas que criam sujeitos 
e subjetividades como normais e naturais por meio da produção de outros - vistos então como perversos ou patológicos. O queer mantém, portanto, sua resistência aos regimes da normalidade, mas reconhece a necessidade de uma epistemologia do que é visto ou tido como desprezível, baseada em investigações interseccionais.

Luce Irigaray (1997), filósofa, psicanalista e linguista, vai bem além das reivindicações e propostas do feminismo hegemônico ao defender a especificidade de uma subjetividade feminina plural. A autora explica que, embora a língua tenha dois gêneros, na verdade esta se baseia apenas em um, o masculino, que atua como a única e universal referência. A seu ver, as civilizações patriarcais reduziram a tal ponto o valor do feminino que a realidade e as suas descrições do mundo são inexatas, já que nascem da ideologia de submissão feminina.

Portanto, não se pode buscar uma simetria entre homens e mulheres, porque essa é inexistente. Em lugar de ser um gênero diferente, o feminino tornou-se, (não apenas) nas línguas latinas, o não-masculino, isto é, uma realidade abstrata não existente, e, consequentemente, uma realidade múltipla. Segundo Luce Irigaray (1997), é afirmando a diferença que a mulher pode se libertar da dominação do sistema patriarcal e assim conquistar uma subjetividade autônoma.

Para a construção de uma ética da diferença sexual, Irigaray recorre ao conceito de Descartes, a admiração/espanto da primeira paixão, que respeita e exalta a diferença mantendo entre o feminino e o masculino um espaço livre e atraente, um espaço que possibilite a separação e a aliança. (SANTOS, 2008: 12).

Enquanto no domínio patriarcal a visão de mundo é marcada pelo olhar, a maneira feminina de ser e estar no mundo é preponderantemente sensual, isto é, através de todos os sentidos, através da sexualidade distinta e da sua corporalidade.

\section{CONSIDERAÇÕES FINAIS E NOVOS QUESTIONAMENTOS}

No contexto de uma teoria feminista hegemônica e branca (isto é, dentro de uma perspectiva igualitarista), o feminismo buscou reivindicar para as mulheres posições equitativas e comparáveis às dos homens e representar as mulheres nos termos da sua equivalência perante os homens. Esses projetos reivindicatórios pela igualdade de direitos e responsabilidades entre os 
sexos (ou classes ou raças) convocam uma concepção de "dignidade humana", "direitos humanos", no qual a igualdade pode ser medida e legislada. Surgem assim projetos que buscam um salto semântico para se construir uma linguagem mais sensível à não-discriminação de gênero. A título de exemplo, vejamos as recomendações para um uso não-sexista da linguagem:

\begin{tabular}{|c|c|}
\hline Quando o homem não tem saúde tudo é mais difícil & NÃO RECOMENDADO \\
\hline Quando alguém não tem saúde tudo é mais difícil & RECOMENDADO \\
\hline Se o homem ouve rádio se anima um pouco & NÃO RECOMENDADO \\
\hline Se alguém ouve rádio se anima um pouco & RECOMENDADO \\
\hline Quando o homem se confunde ao fazer algo & NÃO RECOMENDADO \\
\hline $\begin{array}{l}\text { Quando qualquer pessoa se confunde ao fazer algo } \\
\text { (VENEGAS FRANCO; PÉREZ CERVERA, 2006: }\end{array}$ & RECOMENDADO \\
\hline
\end{tabular}

O salto semântico, nesse caso, dá-se ao trocar o masculino genérico por outras palavras que têm o mesmo sentido e que podem ser usadas sem a marca de um gênero específico (VENEGAS FRANCO; PÉREZ CERVERA, 2006). O alargamento dos estudos de gênero levou muitas feministas a sentir a questão de gênero com desconfiança ao nível das práticas institucionais, pois cria uma simetria (ilusória) entre os sexos, reificando uma visão dicotômica e essencialista em torno do conceito de gênero.

Os estudos teóricos queer não constroem um discurso a favor da simetria entre os sexos. Segundo essa concepção, é equivocado se pensar que os sexos femininos e masculinos são complementares e concordantes entre si, pois entre o sentir sexual masculino e o feminino existe uma radical dissimetria. Homem e mulher devem aprender a se relacionar um com o outro como “diferentes", embora vistos e sentidos como não-hierarquizados superior ou inferiormente.

As posições relativas a um "feminismo da diferença", habitualmente associadas à perspectiva teórica queer, podem servir de exemplo para o segundo entendimento de diferença, em que homens e mulheres deixam de ser considerados como entidades tendencialmente, ou essencialmente, complementares, abrindo espaços para formas complexas de ser. Tal espaço poderia ser pensado como disponível para alojar novas subjetividades, um outro sentir sexual, para além do prazer e do desejo, oposto à sexualidade vitalista baseado na complementariedade entre os sexos.

As perspectivas teóricas queer promovem uma notável confirmação do entendimento primeiro das diferenças: existem, a princípio, não apenas duas entidades - homem e mulher - mas múltiplas subjetividades, inclusive as subjetividades LGBTQ (Gay-Lésbicas-Bi-Transexuais-Queer), 
que podem ser estudadas interseccionalmente em função de um ideal humanista que abre espaço para outras formas de existir.

A língua é um instrumento simbólico em evolução constante. Certamente a língua e a linguagem podem ser adaptadas às nossas necessidades de criar uma sociedade mais justa, diferente e equitativa. Portanto, se as línguas têm raízes, essas raízes são aladas. As inovações tecnológicas nos trouxeram muitos novos conceitos, uma nova linguagem gerada, entre outros aspectos, pelo uso do computador e da internet (e-mail, chat, web, whatsapp etc.). Também a atuação profissional de mulheres em cargos que antes lhes seriam vetados ou de difícil acesso fez com que novas palavras surgissem: ministras, executivas, presidentas. Estes são alguns exemplos de uma mudança no uso da linguagem: o que se considerava um erro gramatical, hoje aparece como algo cotidiano. Talvez essas novas subjetividades e as mudanças sociais possam contribuir para a construção de uma língua mais plural e sensível às diferenças de gênero e subjetividades.

A perspectiva teórica queer nos oferece novos impulsos revisionistas ao mostrar a relatividade de posturas menos essencialistas. No entanto, cabe aqui mencionar o risco de uma aporia teórica, já que o receio exacerbado de essencializar dicotomias pode nos levar ao absolutismo da relatividade. Apesar da crítica teórica, sua relação com a língua portuguesa e as novas perspectivas de compreensão de subjetividades trazidas, entre outras, pela perspectiva queer, verificamos que questões sociais básicas, não apenas no Brasil mas no mundo ainda permanecem abertas, tais como: a discrepância socioeconômica entre a riqueza de poucas pessoas e a pobreza generalizada; os preconceitos de gênero que se agravam e se essencializam numa intolerância mútua; o racismo presente em todas as sociedades e a exclusão social. A teoria queer apresenta uma proposta desafiadora: interrogar a partir da análise da normalização como as fronteiras da diferença são constituídas, mantidas ou dissipadas. As implicações políticas desses novos saberes permitem compreender e contestar os processos sociais que se utilizam das diferenças como marcadores de hierarquia e opressão.

Submetido para avaliação em 27 de Fevereiro de 2018 Aprovado para publicação em 5 de Agosto de 2018 


\section{BIBLIOGRAFIA}

BORGES, José (2013). Sobre línguas, mundos, gêneros etc. In: BRUNELLI, A. F.; MUSSALIM, F.; FONSECA-SILVA, M. C. (Eds.). Língua, texto, sujeito e (inter)discurso. São Carlos: Pedro \& João Editores. p. 129-140.

BUTLER, Judith. Das Unbehagen der Geschlechter. Berlim: Suhrkamp, 1991.

CALDAS-COULTHARD, C. R. (2015). Caro Colega: exclusão lingüística e invisibilidade. In: Leituras em rede: gênero e preconceito. Florianópolis: Editora Mulheres, 2007, p. 373-389 apud RIBEIRO COLAÇO MÄDER, Guilherme: Masculino genérico e sexismo gramatical. Disponível em: $\quad$ https://repositorio.ufsc.br/bitstream/handle/123456789/158447/336814.pdf sequence $=1$ \&isAllowed $=\mathrm{y}]$

DEGELE, Nina (2005). Heteronormativität entselbstverständlichen: Zum verunsichernden Potenzial von Queer Studies. In: Freiburger Frauen Studien, Vol. 17: 109-133.

DOLESCHAL, Ursula (2002). Das generische Maskulinum im Deutschen. Ein historischer Spaziergang durch die deutsche Grammatikschreibung von der Renaissance bis zur Postmoderne. In: Linguistik Online, Vol. 11, p. 39-70.

DUDEN (1984). Dicionário da Língua Alemã. Volume 4: Die Grammatik. Mannheim, Leipzig, Wien, Zürich.

FOUCAULT, Michel (2005). História da Sexualidade I: a vontade de saber. São Paulo: Graal.

HARTMANN, Jutta (2013). Bildung als kritisch-dekonstruktives Projekt - pädagogische Ansprüche und queere Einsprüche. In: Hünersdorf, Bettina/ Hartmann, Jutta (Org.): Was ist und wozu betreiben wir Kritik in der sozialen Arbeit? Disziplinäre und interdisziplinäre Diskurse. Springer Verlag; Wiesbaden, p. 253- 278.

HARTMANN, Jutta (2012). Institutionen, die unsere Existenz bestimmen: Heteronormativität und Schule. In: Aus Politik und Zeitgeschehen / APuZ „Sozialisation“; 62. Jg, H. 49-50; p. 34-41.

IRIGARAY, Luce (1997). Éthique de la Différence Sexuelle. Paris: Les Éditions de Minuit.

JÜRGENS, Frank (1999). Auf dem Weg zu einer pragmatischen Syntax: Eine vergleichende Fallstudie zu Präferenzen in gesprochenen und geschriebenen realisierten Textsorten. Tübingen: Niemeyer.

KLAPEER, Christine M. (2015). Vielfalt ist nicht genug! Heteronormativität als herrschafts- und machtkritisches Konzept zur Intervention in gesellschaftliche Ungleichheiten. In: Schmidt, F. et al. (Hrsg.): Selbstbestimmung und Anerkennung sexueller und geschlechtlicher Vielfalt. Wiesbaden: Springer Fachmedien, p. 25-44. 
MÄDER, Guilherme Ribeiro Colaço (2015). Masculino genérico e sexismo gramatical. Dissertação de mestrado (orientador: Tarcísio de Arantes Leite). Universidade Federal de Santa Catarina, Centro de Comunicação e Expressão. Florianópolis, SC, 159 p. Disponível em: [https://repositorio.ufsc.br/bitstream/handle/123456789/158447/336814.pdf?sequence=1\&isA llowed $=\mathrm{y}]$

MÖRTH, Anita (2005). Dekonstruktion von Zweigeschlechtlichkeit. Möglichkeit für eine nichtbinäre Thematisierung von Geschlecht in pädagogischen Praxisfeldern unter besonderer Berücksichtigung der universitären Lehre. Karl Franzens Universität Graz.

MISKOLCI, Richard (2009). A Teoria Queer e a Sociologia: o desafio de uma analítica da normalização. Sociologias, Porto Alegre, ano 11, no 21, jan./jun. p. 150-182

NOACK NAPOLES, Juliane (2017). 'Geschlechtsidentität' als elementarpädagogisches Bildungsziel - Eine queertheoretische Betrachtung. In: JB Frauen- und Geschlechterforschung, 12017, pp 53-68.

PUSCH, Luise F (1984). Das Deutsche als Männersprache. Frankfurt am Main.

RICARTE LANZ, Helza (2006). Flexible Persistenz. Dezentralisierung und Handlungsrationalität in Brasilien. Série: Freiburger Sozialanthropologische Studien/Freiburg Studies in Social Anthropology/ Etudes d'Anthropologie Sociale de l'Université de Fribourg. Berlin:LIT Verlag Bd. 13.

SANTOS, Maria Alice Barriga Geirinhas dos (2008). O sentir sexual da diferença: o legado de Luce Irigaray na nova subjectividade. Universidade do Porto, Dissertação de Mestrado (Orientador: Fernando José Pereira, co-orientador: Carlos Vidal), 34 p. Disponível em: https://repositorioaberto.up.pt/bitstream/10216/70418/2/5836.pdf

VENEGAS FRANCO, Paki; PÉREZ CERVERA, Julia (2006). Manual para o uso não sexista da linguagem: $O$ que bem se diz... bem se entende. Disponível em: http://www.observatoriodegenero.gov.br/menu/publicacoes/outros-artigos-e-

publicacoes/manual-para-o-uso-nao-sexista-da-linguagem

WAGENKNECHT, Peter (2004). Heteronormativität. In: Haug, Wolfgang Fritz (Hrsg.): Historische-Kritisches Wörterbuch des Marxismus, Bd. 6/I Hegemonie bis Imperialismus, Hamburg, p. 189-206.

WARNER, Michael (1991). Introduction. Fear of a Queer Planet. In: Social Text 29, p. 3-17.

WHORF, Benjamin Lee (1994). Sprache- Denken- Wirklichkeit, Beiträge zur Metalinguistik und Sprachphilosophie. Reinbek bei Hamburg: Rohwolt Taschenbuchverlag. 